\title{
Um Paciente, Duas Cardiomiopatias
}

\section{One Patient, Two Cardiomyopathies}

\author{
Christopher Strong, ${ }^{10}$ Pedro Freitas, ${ }^{1}$ António Ferreira, ${ }^{1}$ Gustavo Rodrigues, ${ }^{1}$ Miguel Mendes ${ }^{1}{ }^{10}$ \\ Serviço de Cardiologia, Hospital de Santa Cruz, Centro Hospitalar Lisboa Ocidental, Lisboa - Portugal
}

Paciente do sexo masculino, com 50 anos de idade, histórico de hipertensão bem controlada e sem histórico pessoal ou familiar conhecido de doença cardíaca, apresentou dor torácica seguida de síncope durante atividade física extenuante. O eletrocardiograma mostrou taquicardia ventricular monomórfica sustentada. Realizouse cardioversão elétrica, com conversão para ritmo sinusal com ondas Q nas derivações V2-5 e III-aVF (Figura 1). A ecocardiografia transtorácica (ETT) mostrou hipertrofia ventricular esquerda (VE) assimétrica, fração de ejeção (FE) preservada com acinesia apical e ventrículo direito (VD) hipertrabeculado. A angiografia coronariana não mostrou lesões significativas. A ressonância magnética cardíaca confirmou os achados da ETT, mostrando espessura máxima da parede do VE de $17 \mathrm{~mm}$ no septo interventricular (Figura S1 - material complementar), aneurisma apical do VE e inserção anormal dos músculos papilares. O lado direito destacou-se pelas paredes livres e inferiores hipertrabeculadas e hipocinéticas, e VD levemente dilatado com FE reduzida (33\%). Além de apresentar realce tardio transmural no ápice do VE, havia também realce tardio nodular na junção VE/ VD e nas paredes basais livres e inferiores do VD (Figura 2; Vídeos 1-2; Figura S2 do material suplementar). A análise genética encontrou mutação heterozigótica no gene PKP2 (p.Thr50Serfs*61), uma variante patogênica associada à

\section{Palavras-chave}

Displasia Arritmogênica Ventricular Direita; Cardiomiopatia Hipertrófica; Taquicardia Ventricular; Exercício; Síncope; Cardioversão Elétrica; Mutagênese.

\section{Correspondência: Christopher Strong}

Hospital de Santa Cruz - Av. Prof. Dr. Reinaldo dos Santos. 2790-134, Carnaxide, Lisboa - Portugal

E-mail: christopherstrong479@yahoo.com

Artigo recebido em 01/12/2019, revisado em 03/02/2020, aceito em 08/04/2020 cardiomiopatia arritmogênica do VD. ${ }^{1}$ No entanto, nenhuma mutação conhecida nos genes relacionados à cardiomiopatia hipertrófica $(\mathrm{CMH})$ foi encontrada em um painel de 204 genes, com 118 relacionados à $\mathrm{CMH}$. Nenhuma associação foi firmemente estabelecida entre as mutações no gene PKP2 e $\mathrm{CMH} .{ }^{2}$ A sobreposição entre os fenótipos genéticos e da cardiomiopatia é um fenômeno bem conhecido. ${ }^{3}$ Partimos da hipótese de que esse paciente tenha uma mutação adicional no gene $\mathrm{CMH}$ desconhecida ou, menos provavelmente, uma expressão fenotípica de duas cardiomiopatias diferentes no contexto de uma mutação do gene PKP2.

\section{Contribuição dos Autores}

Concepção e desenho da pesquisa e Redação do manuscrito: Strong C; Obtenção de dados: Strong C, Freitas P, Rodrigues G; Análise e interpretação dos dados: Strong C, Freitas P; Revisão crítica do manuscrito quanto ao conteúdo intelectual importante: Strong C, Freitas P, Ferreira A, Rodrigues G, Mendes M.

\section{Potencial Conflito de Interesses}

Declaro não haver conflito de interesses pertinentes.

\section{Fontes de Financiamento}

O presente estudo não teve fontes de financiamento externas.

\section{Vinculação Acadêmica}

Não há vinculação deste estudo a programas de pósgraduação.

\section{Aprovação Ética e Consentimento Informado}

Este artigo não contém estudos com humanos ou animais realizados por nenhum dos autores. 


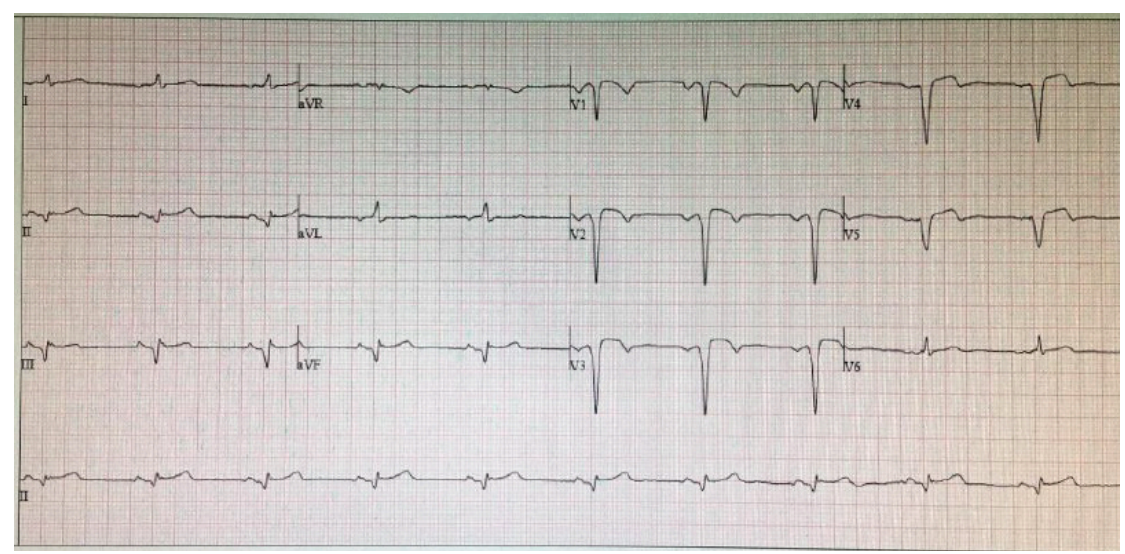

Figura 1 - Eetrocardiograma após cardioversão elétrica.

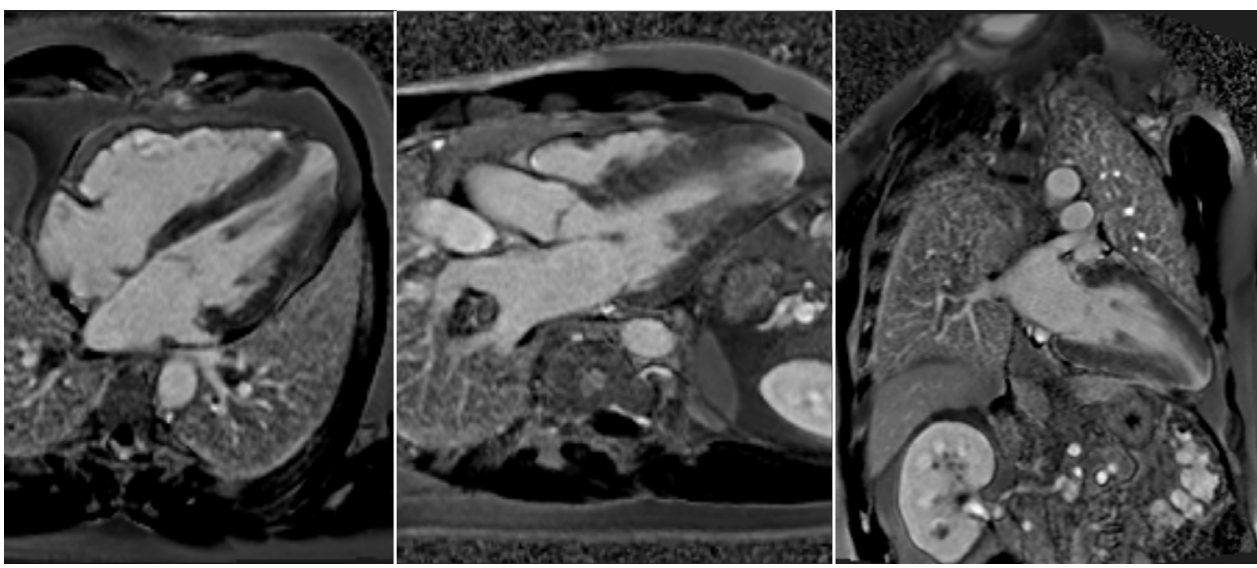

Figura 2 - Ressonância magnética cardíaca - realce tardio no ápice do ventrículo esquerdo e parede livre do ventrículo direito.

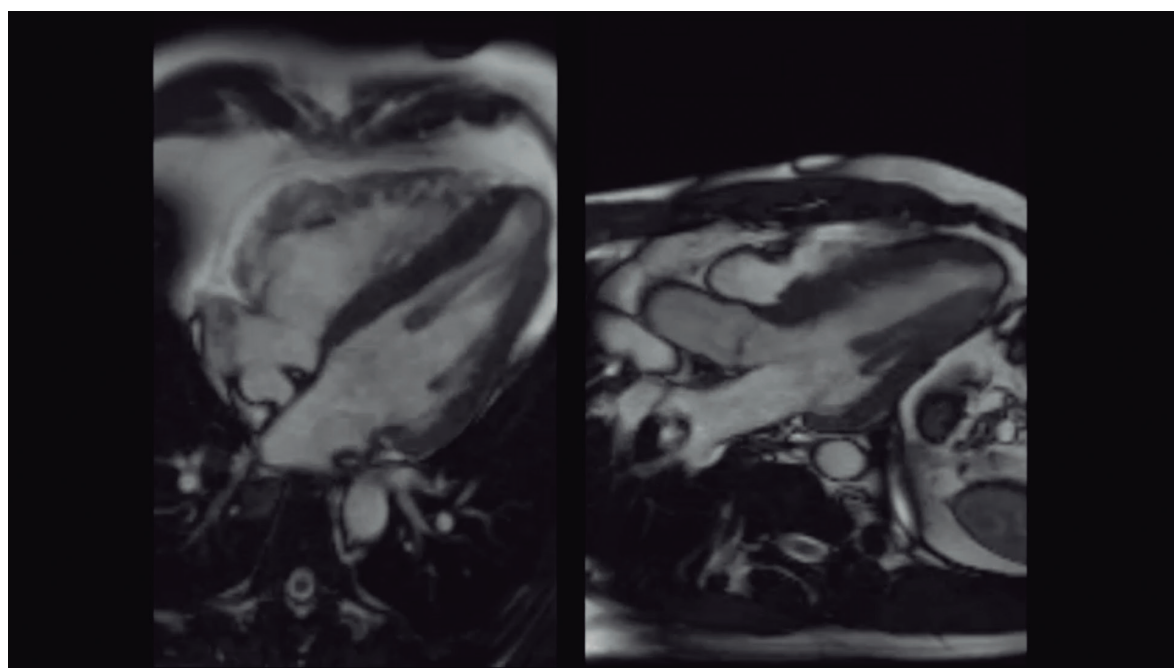

Vídeo 1 - Ressonância magnética cardiaca de 4 câmaras (à esquerda) e 3 câmaras (à direita). URL: http://abccardiol.org/supplementary-material/2020/11503/2019-0853 video01.mp4 


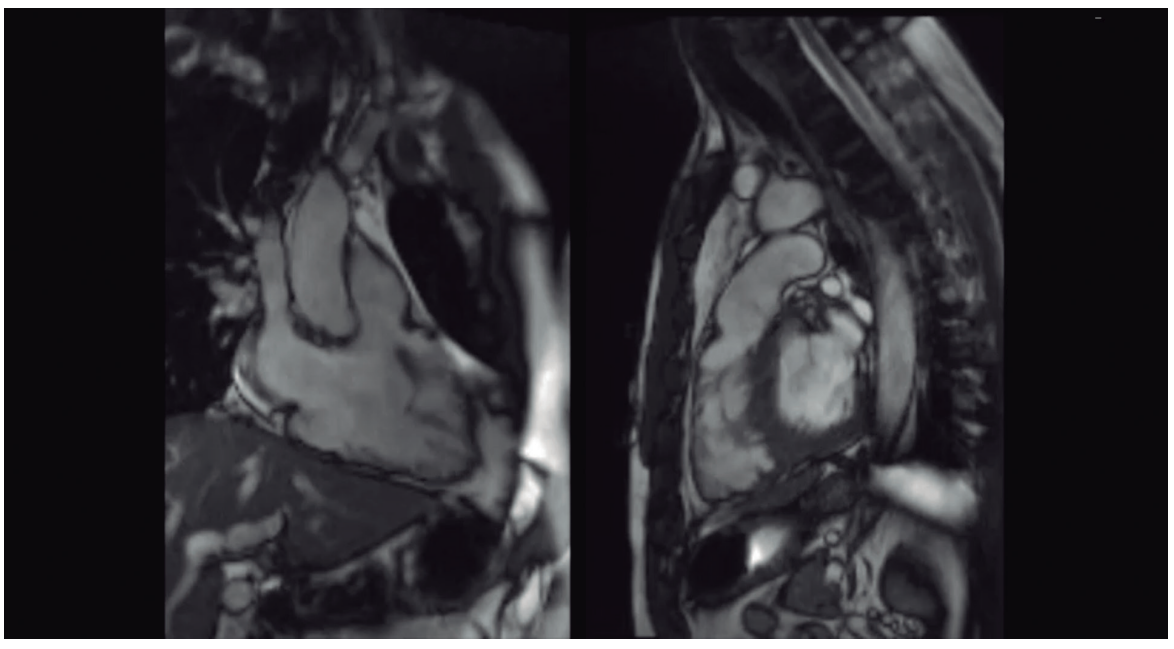

Vídeo 2 - Ressonância magnética cardíaca - vista do trato de saída e entrada do ventrículo direito (à esquerda) e vista de eixo longo do trato de saída do ventrículo direito (à direita). URL: http://abccardiol.org/supplementary-material/2020/11503/2019-0853_video02.mp4

\section{Referências}

1. Wang W, James CA, Calkins H. Diagnostic and therapeutic strategies for arrhythmogenic right ventricular dysplasia/cardiomyopathy patient. Europace. 2019; 21 (1): 9-21.

2. Bainbridge MN, Li L, Tan Y, Cheong BY, Marian AJ. Identification of established arrhythmogenic right ventricular cardiomyopathy mutation in a patient with the contrasting phenotype of hypertrophic cardiomyopathy. BMC Med Genet. 2017; 18 (1): 24.
3. Hershberger RE, Givertz MM, Ho CY, Judge DP, Kantor PF, McBride KL, et al. Genetic Evaluation of Cardiomyopathy - A Heart Failure Society of America Practice Guideline. J Card Fail. 2018; 24 (5): 281-302.

\section{* Material suplementar}

Para informação adicional, por favor, clique aqui. 